\title{
Influence of Operational Timing on the Efficiency of Venting Turbidity Currents
}

\author{
Sabine Chamoun, Ph.D. ${ }^{1}$; Giovanni De Cesare, Ph.D., D.Sc. ${ }^{2}$; and Anton J. Schleiss, Ph.D., D.Sc., M.ASCE ${ }^{3}$
}

\begin{abstract}
Reservoir sedimentation is gaining growing attention as dams are aging, due to economic and environmental consequences. Venting of turbidity currents is one of many sediment management techniques, highly recommended when water is in shortage. The venting operation is experimentally investigated using two reservoir bed slopes. The main research questions concern the opening timing of bottom outlets and the duration of venting. The timings tested are relative to the arrival of the current at the outlet. The results showed that in-time venting, synchronized with the arrival of the turbidity current at the outlet, is more efficient than early or late venting. It is recommended to start opening the gates when the turbidity current is around $300 \mathrm{~m}$ upstream of the outlet, so that the evacuation is synchronized with the arrival of the current at the dam. Additionally, venting should not be stopped immediately after the end of the turbidity current flow but should instead last for a certain time in order to evacuate the muddy lake depending on the outflow discharge. DOI: 10.1061/(ASCE)HY.19437900.0001508. (ㅇ 2018 American Society of Civil Engineers.
\end{abstract}

Author keywords: Reservoir sedimentation; Bottom outlets; Intakes; Management; Turbidity current; Venting; Timing; Duration.

\section{Introduction}

Floods are crucial events for reservoir filling. However, during floods, a large amount of sediments is also transported into reservoirs. As sediments progressively settle and consolidate, reservoirs lose their storage capacity. Sedimentation was observed in many reservoirs in different regions (Morris and Fan 1997). The highest sedimentation rates were observed in China (Wang and $\mathrm{Hu}$ 2009), due to the presence of the Yellow River, the river with the highest sediment load in the world (Morris and Fan 1997). The average annual investment spent to replace the lost reservoir volume due to sedimentation is $\$ 13-\$ 19$ trillion $\left(10^{12}\right)$ (Palmieri et al. 2001; Schleiss et al. 2010, 2016). In the United States, addressing sedimentation by providing extra reservoir capacity, dredging the sediments or replacing the lost storage by new storage reservoirs costs $\$ 690$ million annually (Crowder 1987). The loss of storage directly impacts the energy production of hydropower dams, hinders navigation due to shoaling, and causes unfavorable conditions for fish habitats [(Brown 1950) as cited by Sloff (1991)]. Aside from storage loss, sedimentation may also cause bottom outlet and intake clogging [e.g., Rempen and Mauvoisin dams in Switzerland (Boillat and Pougatsch 2000)], abrasion of hydraulic machinery [e.g., Gebidem and Mauvoisin dams in Switzerland (Boillat et al. 2000)], downstream sediment starvation (Morris and Fan 1997) and its ecological consequences (Wüest 2010).

${ }^{1}$ Laboratory of Hydraulic Constructions, Ecole Polytechnique Fédérale de Lausanne, Station 18, CH-1015 Lausanne, Switzerland (corresponding author). Email: sabine.chamoun@epfl.ch

${ }^{2}$ Laboratory of Hydraulic Constructions, Ecole Polytechnique Fédérale de Lausanne, Station 18, CH-1015 Lausanne, Switzerland. Email: giovanni .decesare@epfl.ch

${ }^{3}$ Professor, Laboratory of Hydraulic Constructions, Ecole Polytechnique Fédérale de Lausanne, Station 18, CH-1015 Lausanne, Switzerland. Email: anton.schleiss@epfl.ch

Note. This manuscript was submitted on June 19, 2017; approved on March 28, 2018; published online on July 9, 2018. Discussion period open until December 9, 2018; separate discussions must be submitted for individual papers. This paper is part of the Journal of Hydraulic Engineering, (C) ASCE, ISSN 0733-9429.
Previously, overdesigning the reservoir volume with so-called dead storage was considered to be a way to delay the consequences of sedimentation. However, the cost of a cubic meter of stored water is continuously increasing not only due to the rising construction costs, but mainly because low-cost sites available for dams are gradually disappearing (Vanoni 2006). Today, new dams are being designed with greater awareness in view of potential sedimentation. This leads to the need for drawing up operational guidelines and also for investigating sediment mitigation techniques that are applied for reservoirs in operation as well as planned for those under construction (Schleiss et al. 2016). These techniques aim to reduce the amount of sediments inside reservoirs, to restore the lost water volumes and to replenish the downstream river (Kantoush and Sumi 2010). Different techniques are used to reach this goal. In some cases, sediments are mechanically dredged and transported from upstream to downstream of the dam, while in other cases, sediments are withdrawn or relocated in reservoirs. If the reservoir has sufficient runoff compared to the storage volume, flushing is applied (Antoine et al. 2013; Brandt 2000; Espa et al. 2016). It consists of drawing down the reservoir's level, allowing for retrogressive erosion and therefore the evacuation of part of the sediments through outlets (Wen Shen 1999). Flushing can be also combined with mechanical dredging in order to loosen the sediments.

However, in narrow and long reservoirs, fine sediments are transported by sediment-laden currents called turbidity currents. They can travel all along the reservoir until reaching the dam, depending on the geometric characteristics of the thalweg and on their sediment concentrations (De Cesare et al. 2001; Graf and Altinakar 1995; Meiburg and Kneller 2010). Unless bottom outlets or intakes are opened to evacuate the sediments, the latter form a muddy lake and settle near the dam. In such cases, the most highly recommended method for the mitigation of sediments is the venting of turbidity currents through bottom outlets (Chamoun et al. 2016a). This consists of opening the bottom outlet with relatively small discharges (Chamoun et al. 2016b) and transiting the approaching turbidity current to the downstream river. Venting is known to be relatively economical and environmentally friendly (Palmieri et al. 2003). 
Nevertheless, despite its potential effectiveness, venting has not been widely researched. Dam operators are in need of further practical operational guidelines that can be applied during venting. Several researchers have discussed the importance of the technique of venting and endorsed it, but very few have conducted quantitative research (Chamoun et al. 2017a; Fan 1960, 1986; Lee et al. 2014; Yu et al. 2004). However, the most influential parameters of venting can be concluded based on field experiences and data (Chen and Zhao 1992; Morris and Fan 1997; Wang and Hu 2009) published in the literature. These parameters include the outlet's discharge during venting (Chamoun et al. 2017a; Lee and Yu 1997; Morris and Fan 1997); the geometric characteristics of the reservoir, notably the bed slope affecting the dynamics of the approaching current in the vicinity of the dam; the duration of venting (Basson and Rooseboom 1997); the number, dimensions, and position of the low-level outlets; as well as the timing of the opening of the outlet (Chen and Zhao 1992). In previous publications, the authors have investigated the systematic effect of the outlet's discharge (Chamoun et al. 2017a) and the influence of different bed slopes (Chamoun et al. 2017b) on the sediment release efficiency of venting. Based on these investigations, favorable conditions were drawn on the outlet's opening and topographic conditions close to the outlet. However, while the concerned parameters were varied in the mentioned work, only one venting timing was used, synchronized with the arrival of the turbidity current at the outlet. The information found on venting timing was mostly qualitative or based on scarce field data. No scientific assessment was performed despite the net importance of this parameter. Timing was not quantitatively studied in the last few years, to the knowledge of the authors. With appropriate timing of the gate opening, it is possible to vent high sediment loads carried by turbidity currents (Annandale 2005; Wan et al. 2010). Valuable water might be lost if the opening of the outlet is too early or too large, and strong velocity fields of clear water can be formed in front of the outlet (Chen and Zhao 1992). If the gates are opened too late, sediments that could potentially be evacuated might settle before their evacuation, rendering the operation less efficient. The right time for venting is the time at which the reservoir's trap efficiency is minimized. This optimal timing with minimized loss of useful clear water strongly depends on the estimation of the travel duration of the turbidity current along the reservoir, from the plunge point to the dam. For instance, in the Rio Grande Reservoir, Fiock (1934) stated that given the size of the reservoir, silty water is detected in the outflow two to five days after the density current has entered the reservoir. An underestimation of this relatively long traveling time can generate significant water losses. In 1953, Brune mentioned that welltimed venting operations can triple or quadruple the amount of sediments evacuated from reservoirs. A well-timed venting at Lake Issaqueena in the United States increased the amount of evacuated sediments by $174 \%$ (Brune 1953). In the Heisonglin reservoir in China where venting is applied during dry periods, a very late opening of gates is considered as one of the reasons leading to low sediment release efficiency (Morris and Fan 1997). However, the exact time at which the turbidity current reaches the dam is rarely measured in reservoirs where venting is applied. To obtain better information at the dam site, it is highly recommended to take velocity or concentration profile measurements over the reservoir's depth near the dam, particularly during yearly flood events that may trigger turbidity currents. Possible mounting procedures and settings were mentioned by Müller (2012) and Schneider et al. (2007). Furthermore, in the possibility of venting, operators not only wonder when to start the operation, but also when to stop it in order to avoid high water loss.
In the present study, the influence of the timing of outlet opening on the sediment release efficiency of venting turbidity currents is investigated experimentally. The different timings tested are relative to the arrival of the turbidity current at the outlet. Additionally, two tests were undertaken where turbidity currents were not continuously fed during venting. In the following, the experimental apparatus and sediment material are described, followed by the description of the testing procedure, the measuring instruments used, and an overview of the experimental parameters and test characteristics. The results including the temporal variations of the sediment release efficiency, outflow concentration, and deposition are then discussed. Finally, conclusions and a discussion are presented.

\section{Method}

\section{Experimental Apparatus}

Turbidity currents are generated in a narrow $(0.27-\mathrm{m})$ flume that is $8.55 \mathrm{~m}$ long and $1 \mathrm{~m}$ high. In Fig. 1(a), the main flume (Number 7) simulates the reservoir in which turbidity currents travel. The water-sediment mixture is prepared in a mixing tank (Number 5) from which it is pumped into the head tank (Number 6) of the flume through a pumping pipe (Number 2). Note that the mixing tank is equipped with a submerged pump that keeps the sediments suspended before and during the test. The mixture can also flow from the head tank to the mixing tank through a restitution pipe (Number 1). A valve is placed at this pipe for flow control. The head tank and the main flume are separated by a wall with an opening at its bottom serving as an inlet ( $4.5 \mathrm{~cm}$ high).

At a distance of $6.7 \mathrm{~m}$ from the inlet, a wall is placed representing the dam with a bottom outlet, which is centered on the width of the flume. It is $12 \mathrm{~cm}$ high and $9 \mathrm{~cm}$ wide. The height of the wall is $80 \mathrm{~cm}$ when using the $2.4 \%$ slope and $92 \mathrm{~cm}$ for the $5.0 \%$ slope. Moreover, downstream of the wall, a compartment (Number 8) serves as a container for the residual clear water spilling from the main flume during the turbidity current flow. Finally, a downstream tank (Number 9) is placed at the exit of the venting pipe (Number 3) and receives the vented turbidity current.

In case the outflow is greater than the inflow and to avoid the decrease of the water level in the main flume, part of the spilled clear water in the downstream compartment of the flume is pumped back into the main flume through a recirculation pipe (Number 4). A diffusor placed above the inlet [Fig. 1(c)] receives the residual clear water and divides it over its height.

\section{Sediment Materia}

The sediment material mixed with the water is a fine polymer (thermoplastic polyurethane) characterized by a particle density of $\rho_{s}=1,160 \mathrm{~kg} / \mathrm{m}^{3}$, and diameters of $d_{10}=66.5 \mu \mathrm{m}, d_{50}=$ $140 \mu \mathrm{m}$, and $d_{90}=214 \mu \mathrm{m}\left(d_{\mathrm{x}}\right.$ representing the grain size diameter for which $\mathrm{x} \%$ of the sediments has smaller diameters). The settling velocity $v_{s}$ of the sediment material is represented by the settling velocity of the $d_{50}$ diameter estimated at $1.5 \mathrm{~mm} / \mathrm{s}$.

In experimental modeling, scaling is an important question. Since sediments highly influence the dynamics of the turbidity currents, care was taken to choose adequate material to minimize the scale effects. In the present case, diameters are closely similar to prototype conditions while the particle density is reduced to enable the suspension of the sediments and therefore the formation of the currents. The main criteria to assess the validity of the choice of the different parameters (i.e., particle density, concentration, inflow discharge, and concentration) is Reynolds number $R$, which is assessed through the velocity measurements. A $R>2000$ indicates 
(1) Restitution pipe

(2) Pumping pipe

(3) Venting pipe

(4) Recirculation pipe

(5) Mixing tank

(6) Head tank

(7) Main flume

(8) Downstream compartment

(9) Downstream tank

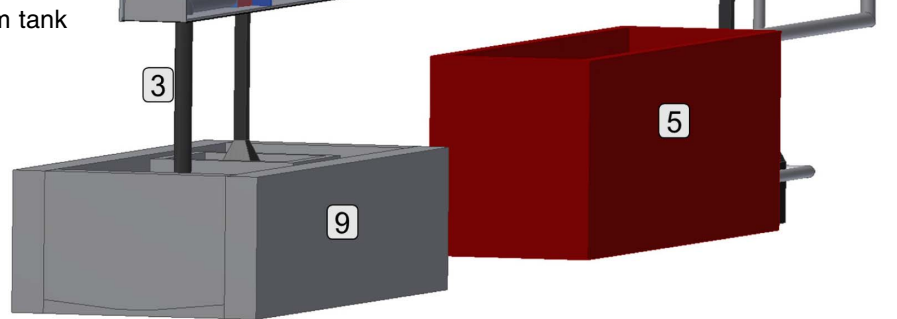

(a)

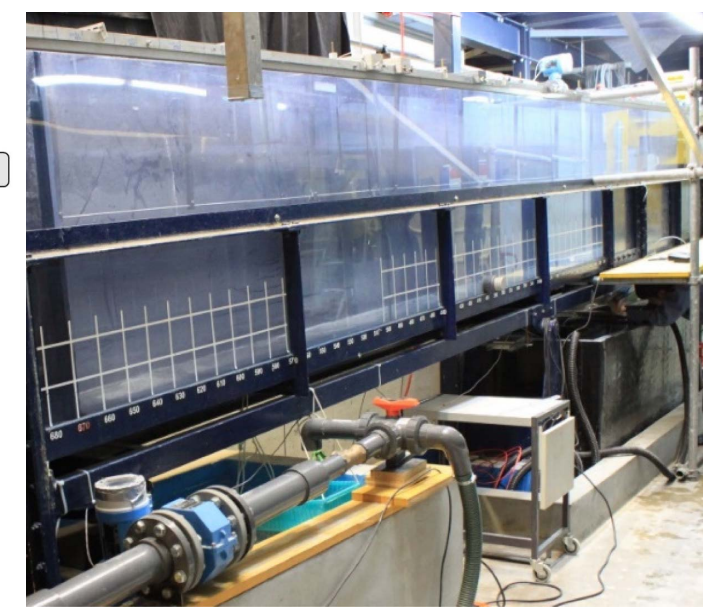

(b)

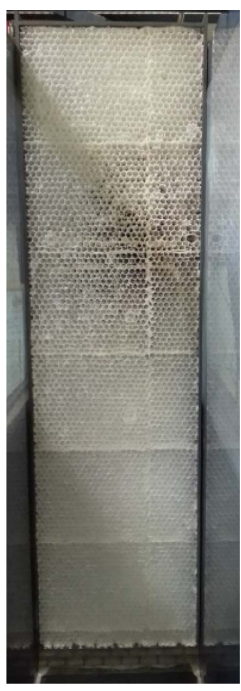

(c)

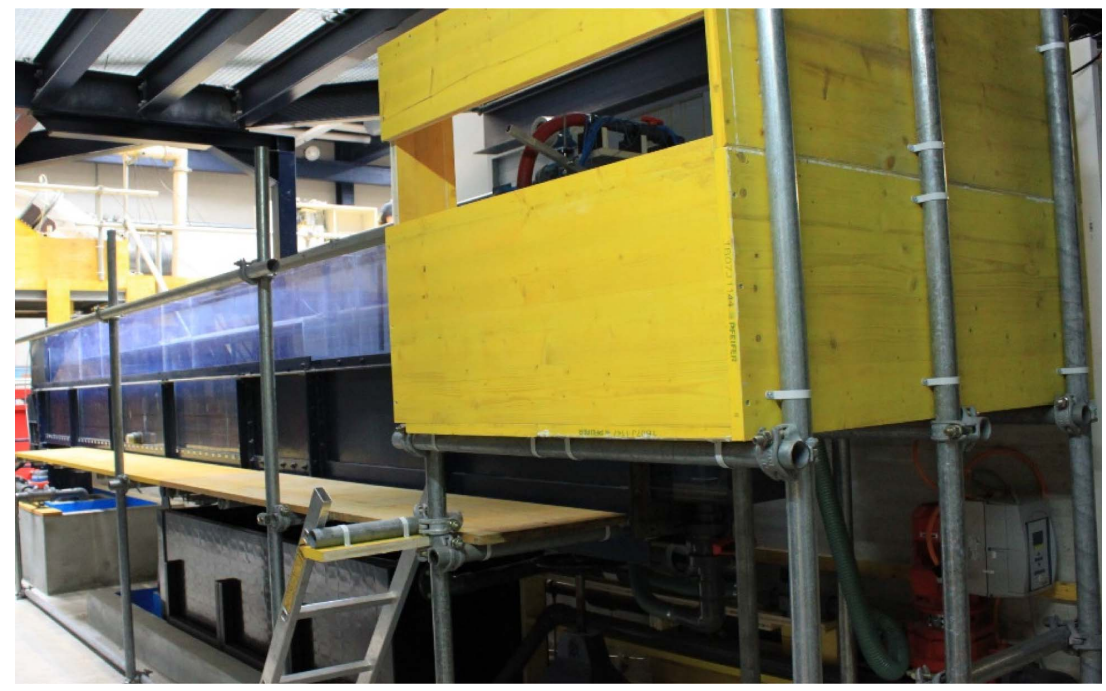

(d)

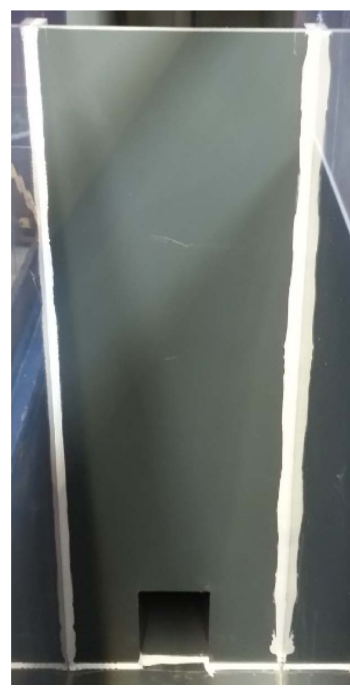

(e)

Fig. 1. (a) 3D illustration of experimental set-up showing its different pipes and tanks; (b) downstream view of flume; (c) inlet and diffusor (honeycomb-shaped); (d) upstream view of flume; and (e) downstream wall and bottom outlet.

that the turbidity current is fully turbulent and thus applying Froude similarity is possible (Kneller and Buckee 2000). Additionally, the geometric width-height ratio applied to the outlet $(3: 4)$ is in the same range of dimensions found in the prototype.

\section{Measurements}

During the tests, several instruments were used to monitor different parameters. Notably, the inflow and outflow volumetric concentrations $C_{T C}$ and $C_{V E N T}$, the turbidity current's inflow and venting discharges $Q_{T C}$ and $Q_{V E N T}$, the deposition mass $m_{d e p}$, and velocity profiles. The parameters measured by each instrument and the goal of the measurements are given in Table 1 . The position of the instruments in the experimental set-up is shown in Fig. 2. Note that only some of the bottom deposition electrodes are shown. They are placed throughout the flume starting $10-620 \mathrm{~cm}$ from the inlet and separated by $10 \mathrm{~cm}$ (Chamoun et al. 2016c; Oehy 2003).

Note that the average temperature difference was around $2.5^{\circ} \mathrm{C}$ corresponding to only $7 \%$ of the density difference due to the suspended sediments.

\section{Experimental Procedure and Parameters}

The experimental procedure of all the tests adheres the following main steps:

1. The main flume is filled with clear water up to the height of the downstream wall $(80 \mathrm{~cm}$ for the bed slope $S=2.4 \%$ and $92 \mathrm{~cm}$ for $S=5.0 \%$ ). Simultaneously, the mixture of water and sediments is prepared in the mixing tank.

2. Once the required amount of sediments (leading to the tested concentration) is added to the mixing tank, the mixture is pumped into the head tank through the pumping pipe and restituted to the mixing tank through the restitution pipe. This recirculation ensures that the mixture is homogeneous between the mixing tank and the head tank. It lasts until reaching the expected concentration of the test in the head tank.

3. The valve placed on the restitution pipe is then closed and the sliding gate opened. This procedure triggers a turbidity current inside the main flume due to the density difference between the mixture and the clear water. The current is then formed in the main flume and travels along the bed until reaching the bottom outlet. 
Table 1. List of the measuring instruments and parameters measured

\begin{tabular}{|c|c|c|}
\hline Instrument & Parameter & Goal of measurement \\
\hline Turbidity probe & $\begin{array}{l}\text { Initial mixture's volumetric concentration } C_{T C} \text { and outflow } \\
\text { concentration } C_{V E N T}\end{array}$ & $\begin{array}{l}\text { Venting efficiency calculation; check of the steadiness of } \\
\text { initial conditions. }\end{array}$ \\
\hline Flowmeter & $\begin{array}{l}\text { Turbidity current discharge } Q_{T C} \text { (pumping pipe), outflow } \\
\text { discharge } Q_{V E N T} \text { (venting pipe) and residual discharge } Q_{R E S} \\
\text { (recirculation pipe) }\end{array}$ & $\begin{array}{l}\text { Venting efficiency calculation; check of the steadiness of } \\
\text { initial conditions. }\end{array}$ \\
\hline Depositometer & Deposition mass $m_{d e p}$ or thickness & $\begin{array}{l}\text { Venting efficiency calculation; characterization of the } \\
\text { turbidity currents (conservative, depositive). }\end{array}$ \\
\hline Level probe & Water level & $\begin{array}{l}\text { Check of stability of levels between the head tank and main } \\
\text { flume; check for the steadiness of initial conditions. }\end{array}$ \\
\hline UVP transducer & Velocity profile (1-D) & $\begin{array}{l}\text { Characterization of the turbidity currents (i.e., velocity, } \\
\text { height, Reynolds number). }\end{array}$ \\
\hline $\begin{array}{l}\text { Electronic } \\
\text { thermometer }\end{array}$ & Temperature & $\begin{array}{l}\text { Measurements are used to check that temperature differences } \\
\text { were not high between the mixture in the head tank and the } \\
\text { clear water in the main flume and therefore the density } \\
\text { difference is majorly due to sediment concentration. } \\
\text { Temperature measurements were also used in the analysis of } \\
\text { the sediment deposition data. }\end{array}$ \\
\hline Camera & Photos and video recordings & $\begin{array}{l}\text { Check the advancement of the turbidity current in space and } \\
\text { time; estimate the front velocity of the current and the } \\
\text { variation of its size. }\end{array}$ \\
\hline
\end{tabular}

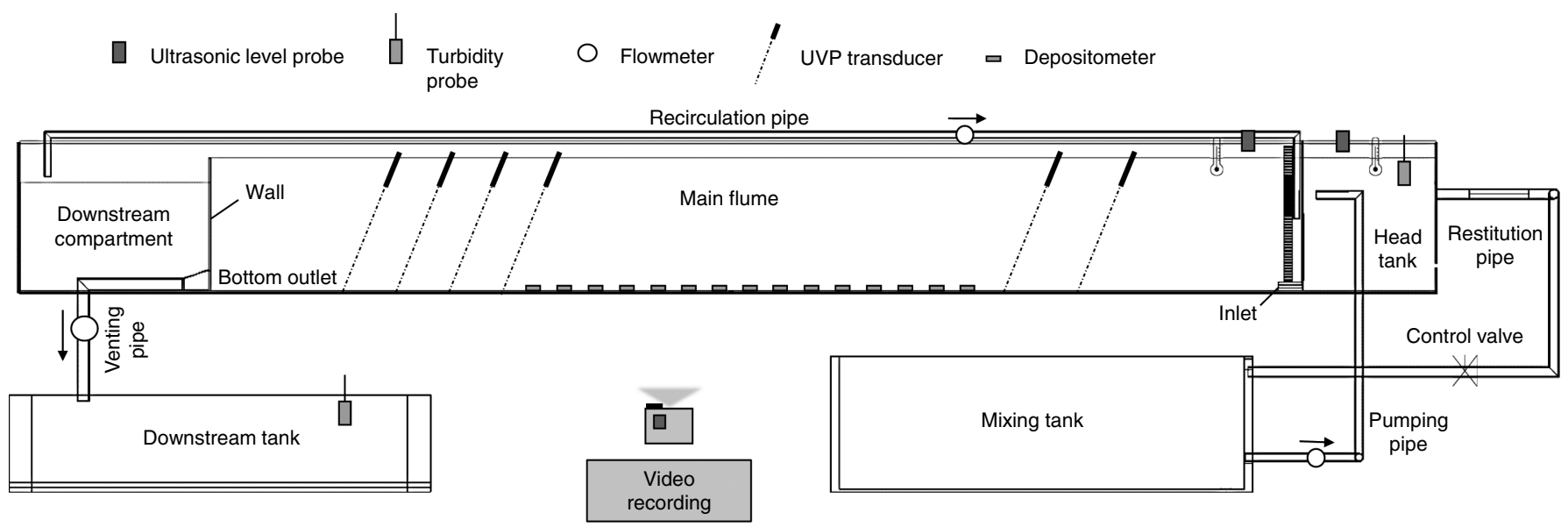

Fig. 2. Experimental set-up with location of different measuring instruments.

4. Depending on the venting timing tested, the bottom outlet is opened and venting starts. The evacuated part of the current then reaches the downstream tank where sediment concentration is measured. In the case where the outflow (venting) discharge $Q_{V E N T}>$ turbidity current's inflow discharge $Q_{T C}$, a residual clear water discharge $Q_{R E S}=Q_{V E N T}-Q_{T C}$ is ejected from the downstream compartment to the main flume through the recirculation pipe.

5. In two cases, the inflow was stopped during venting. The upstream pump was stopped and the sliding gate closed while venting was maintained.

The tests performed in the present study investigated the influence of two of the most important operational parameters related to venting on the efficiency of the operation: the timing and the duration. Therefore, an important aspect was to ensure relatively similar turbidity currents while varying the operational parameters. To do so, the volumetric inflow concentration $C_{T C}$ and inflow discharge $Q_{T C}$ of the turbidity current were kept as steady as possible from one test to another and during the same test. Moreover, water levels at the head tank and in the main flume were kept as equal and steady as possible during the tests.
Hereafter are the main parameters discussed in this work:

- Two bed slopes $S$ were tested: 2.4 and 5.0\%. The thalweg slope in the vicinity of the outlet near the dam varies throughout the lifetime of a reservoir or when considering sediment deposition. This slope mainly depends on the frequency of the outlet's opening to release sediments in front of the outlet. The slope can affect the dynamics of turbidity currents reaching the outlet near the dam. Hence, it was important to test two different slopesin the range of prototype slopes - and check whether or not the effect of the opening timing (the main parameter) is slopedependent.

- Four different venting timings (Figs. 3 and 4) were investigated relative to the arrival of the turbidity current's head at the wall: (1) the outlet is opened before the arrival of the current at the outlet (early venting) at a distance of $d / h_{\text {outlet }}=5$ where $h_{\text {outlet }}=12 \mathrm{~cm}$ is the height of the bottom outlet. This distance was chosen to allow enough time for the outlet's flow field to develop in order to assess its effect on the vented current; (2) the outlet's opening is synchronized with the arrival of the turbidity current's head at the outlet (in-time venting); (3) the outlet is opened $30 \mathrm{~s}$ after the arrival of the current at the wall, once 


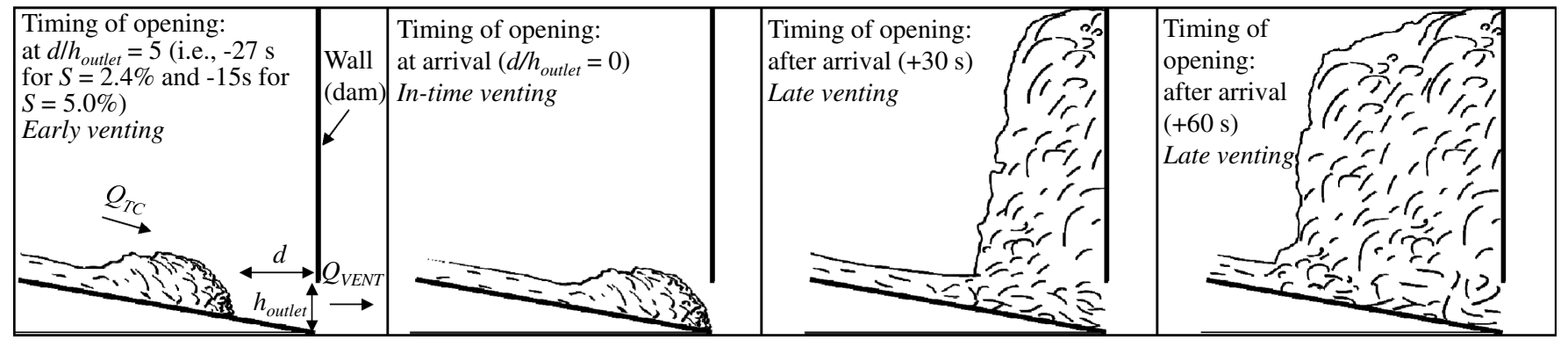

(a)

(b)

(c)

(d)

Fig. 3. Four venting timings tested: (a) early venting; (b) in-time venting; (c) $30 \mathrm{~s}$ late venting; and (d) $60 \mathrm{~s}$ late venting.

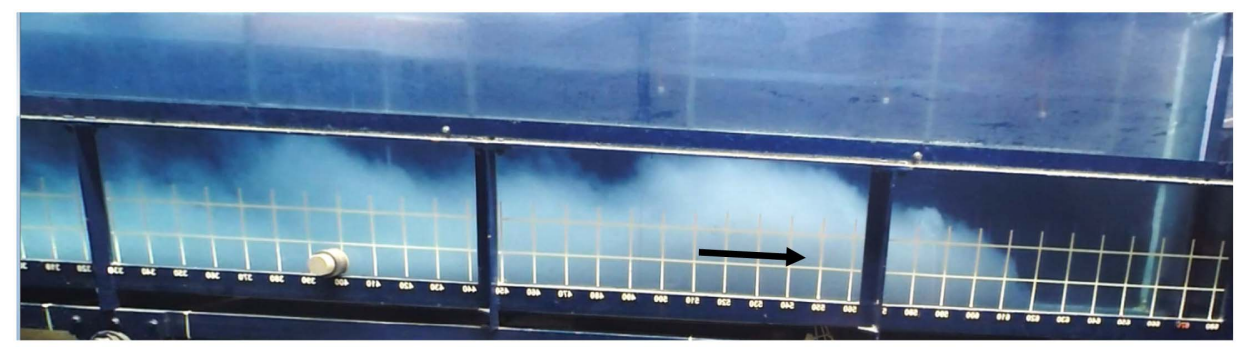

(a)

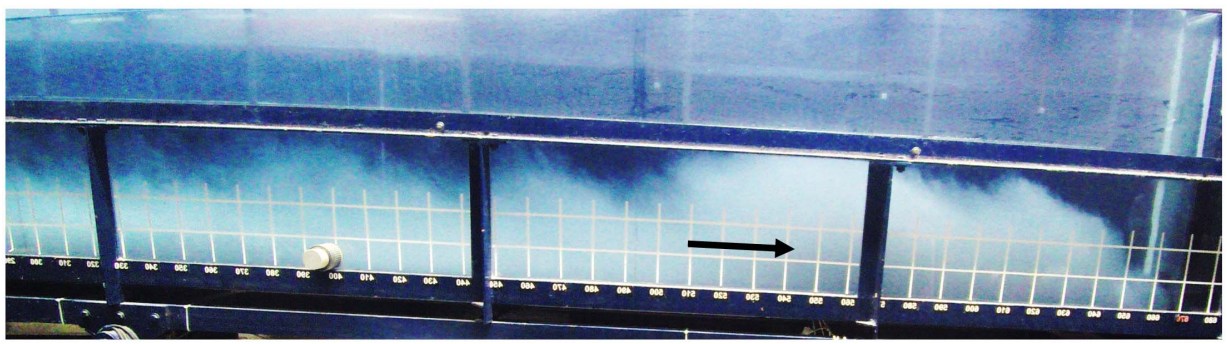

(b)

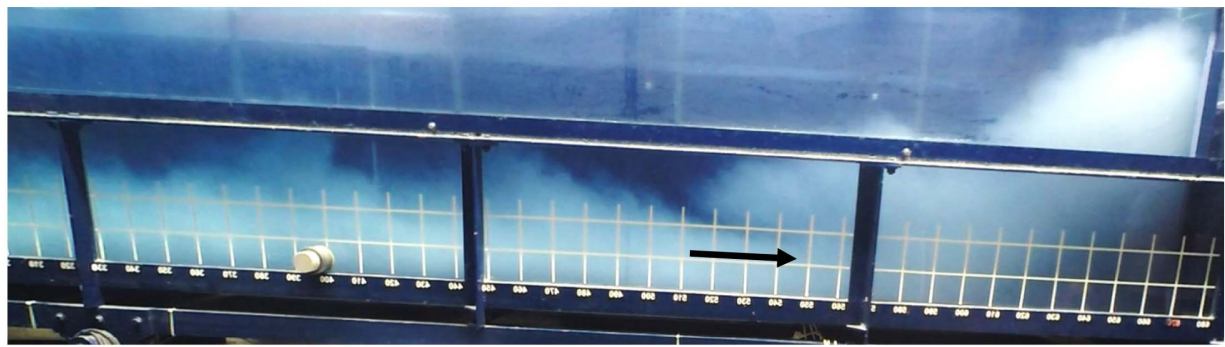

(c)

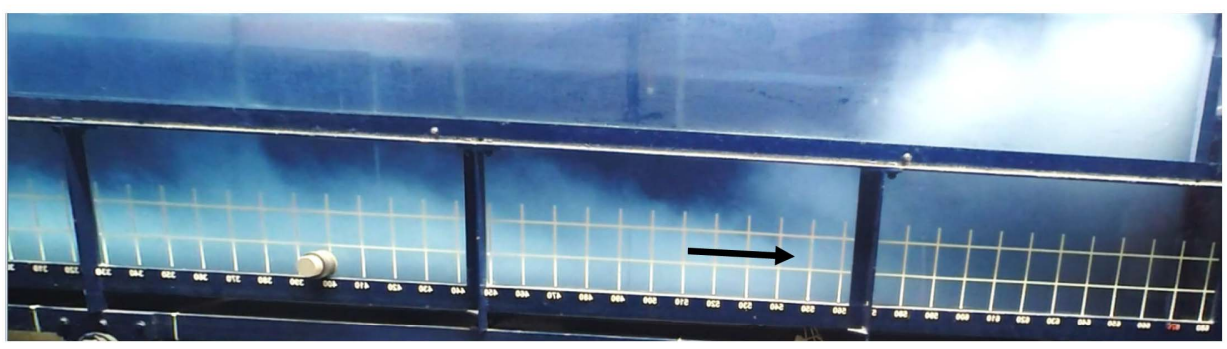

(d)

Fig. 4. Four different timings tested: (a) early venting; (b) in-time venting; (c) $30 \mathrm{~s}$ late venting; and (d) $60 \mathrm{~s}$ late venting (test S2.1).

it has reached its top and started reflecting (30 s late venting); and (4) the outlet is opened $60 \mathrm{~s}$ after the arrival of the current at the wall and the beginning of the retrogressive reflection of the muddy lake (60 s late venting).
- Turbidity current inflow: the inflow was interrupted for two tests during venting (tests S2.7 and S2.8). The flow interruption corresponds to the end of the flood when the turbidity current's inflow in prototype has stopped. It was simulated in order to 
check whether or not venting should be maintained after the end of the turbidity current inflow. The inflow interruption was timed nearly $130 \mathrm{~s}$ after the beginning of venting. The moment of the interruption had to be chosen based on experimental criteria. The interruption should not occur too early, before the formation of the muddy lake and the beginning of the reflection of the current. The interruption should not occur too late either so that venting after the interruption can last the longest possible time, taking into account the capacity of the downstream basin. For the rest of the tests, the inflow was continuous throughout the test.

\section{Description of Tests and Analysis Methodology}

Details of the different tests are given in Table 2. The venting degree $\Phi$ is defined as the ratio between the outlet's discharge $Q_{V E N T}$ and the turbidity current's inflow discharge $Q_{T C}, \rho_{t 0}$ is the initial density of the turbidity current, $g_{0}^{\prime}=g C_{T C}\left(\left(\rho_{s}-\rho_{w}\right) / \rho_{w}\right)$ is the reduced gravity of the inflowing turbidity current where $g$ is the gravitational acceleration, $C_{T C}$ is the volumetric inflow concentration of the turbidity current and $\rho_{w}$ is the density of the clear water. Finally, $B_{0}$ is the initial buoyancy flux of the current expressed by $B_{0}=g_{0}^{\prime} q_{T C}\left(q_{T C}\right.$ is the initial specific discharge of the current) (Graf and Altinakar 1995).

Two criteria were used to evaluate the efficiency of venting:

- In terms of sediment release: a criterion previously defined by Chamoun et al. (2017a) called the Local Venting Efficiency (LVE) was used. This efficiency is local because it only evaluates the total mass of sediments vented compared with the total mass of sediments that can be potentially vented. The latter is the total mass of inflowing turbidity current sediments from which the total mass of deposited sediments is subtracted. In fact, due to the relatively low outflow discharge of the bottom outlet during venting, the reservoir's level is not lowered and so the deposited sediments along the reservoir cannot be eroded and evacuated during venting.

- In terms of sediment release and water loss: a criterion also defined by Chamoun et al. (2017a) called the Venting Efficiency Indicator (VEI) was used. Using the LVE, only sediment volumes/masses are accounted for. However, the assessment of the loss of water resulting from venting is of great interest for reservoir operators. Hence, a global concentration of the evacuated flow is calculated through the ratio between the sediment volume and the clear water volume released. This global concentration is multiplied by the LVE, resulting in the VEI.
In addition, the duration of venting was normalized by linking it to some crucial venting parameters as defined and described by Chamoun et al. (2017a), mainly to allow for comparison with other possible research and applications on venting. The LVE and the VEI are plotted relatively to $\bar{t}=\left[\left(t-T_{v i}\right)^{2} g_{a p p}^{\prime}\right] / h_{L}$. In this equation, $g_{a p p}^{\prime}$ is the reduced gravity acceleration of the current approaching the outlet, $h_{L}$ is the outlet's aspiration height, and $T_{v i}$ the initial time of venting. The aspiration height $h_{L}$ defines the upper and lower limits that the outlet's flow field can reach above and below the central axis of the outlet. In other words, if the height of the turbidity current reaching the outlet is below the lower limit of the height of aspiration, the current cannot be vented.

Note that the equations defining the LVE, the VEI and the normalized duration of venting $\bar{t}$ can be found in Eqs. (A.1), (A.2), and (A.3), respectively, of the appendix attached to this paper.

\section{Results}

\section{Local Venting Efficiency: Early Venting versus Late Venting}

In the following, the tests with early and late venting are compared based on the LVE (Fig. 5). LVE is plotted as a function of the normalized duration of venting. For both slopes, the LVE reached higher values when venting started before the arrival of the turbidity current at the outlet/wall. Venting before the arrival of the current resulted in higher LVE values probably because the streamlines upstream of the outlet are sufficiently developed to ensure good suction of the currents during their evacuation. In fact, the countercurrent that is commonly formed above the turbidity current was reduced because the outlet's discharge acts in the opposite direction. The current therefore encountered less interface shear stress and the water entrainment into the turbidity current decreased (Cao et al. 2015). Although no visible acceleration of the current was observed when early venting was applied (i.e., -27 s for $S=2.4 \%$ and -15 s for $S=5.0 \%$ ), the head of the current was drawn toward the outlet. At the moment of entering the bottom outlet, the nose of the turbidity current was triangular instead of having the typical curved form (highlighted by the circle in Fig. 6). It was slightly detached from the remaining parts of the current, which then followed into the bottom outlet. Note that this was observed around $15-20 \mathrm{~cm}$ upstream of the outlet, which corresponds to more or less $1.5 h_{\text {outlet }}$, suggesting that the outlet's zone of influence is very

Table 2. Characteristics of the turbidity currents generated and venting conditions

\begin{tabular}{|c|c|c|c|c|c|c|c|c|}
\hline \multicolumn{6}{|c|}{ Inflowing turbidity current } & \multirow{2}{*}{$\begin{array}{l}\text { Venting degree, } \Phi \\
Q_{V E N T} / Q_{T C}(\%)\end{array}$} & \multirow{2}{*}{$\begin{array}{c}\text { Timing of opening } \\
d / h_{\text {outlet }} \text { (early) } \\
\text { or } t_{\text {after }} \text { (late) }\end{array}$} & \multirow[b]{2}{*}{ Inflow } \\
\hline Test & $S(\%)$ & $C_{T C}(\%)$ & $\rho_{t 0}\left(\mathrm{~kg} / \mathrm{m}^{3}\right)$ & $g_{0}^{\prime}\left(\mathrm{cm} / \mathrm{s}^{2}\right)$ & $B_{0}\left(\mathrm{~cm}^{3} / \mathrm{s}^{3}\right)$ & & & \\
\hline S1.1 & 2.4 & 1.67 & $1,002.4$ & 2.63 & 97.8 & 115 & $d / h_{\text {outlet }}=5$ & Continuous \\
\hline $\mathrm{S} 1.2$ & 2.4 & 1.91 & $1,002.7$ & 3.00 & 110.0 & 100 & $d / h_{\text {outlet }}=0$ & Continuous \\
\hline S1.3 & 2.4 & 2.16 & $1,003.1$ & 3.40 & 123.7 & 135 & $d / h_{\text {outlet }}=0$ & Continuous \\
\hline S1.4 & 2.4 & 2.36 & $1,003.4$ & 3.71 & 130.7 & 115 & $t_{a f t e r}=30 \mathrm{~s}$ & Continuous \\
\hline S1.5 & 2.4 & 2.41 & $1,003.5$ & 3.80 & 138.3 & 115 & $t_{\text {after }}=60 \mathrm{~s}$ & Continuous \\
\hline S2.1 & 5.0 & 2.40 & $1,003.5$ & 3.77 & 138.1 & 115 & $d / h_{\text {outlet }}=5$ & Continuous \\
\hline $\mathrm{S} 2.2$ & 5.0 & 2.26 & $1,003.3$ & 3.56 & 132.8 & 100 & $d / h_{\text {outlet }}=0$ & Continuous \\
\hline S2.3 & 5.0 & 2.37 & $1,003.5$ & 3.74 & 137.5 & 115 & $d / h_{\text {outlet }}=0$ & Continuous \\
\hline S2.4 & 5.0 & 2.15 & $1,003.1$ & 3.39 & 123.0 & 135 & $d / h_{\text {outlet }}=0$ & Continuous \\
\hline S2.5 & 5.0 & 2.24 & $1,003.2$ & 3.53 & 128.7 & 115 & $t_{a f t e r}=30 \mathrm{~s}$ & Continuous \\
\hline S2.6 & 5.0 & 2.26 & $1,003.3$ & 3.56 & 132.8 & 115 & $t_{\text {after }}=60 \mathrm{~s}$ & Continuous \\
\hline S2.7 & 5.0 & 1.9 & $1,002.7$ & 3.0 & 110.3 & 30 & $d / h_{\text {outlet }}=0$ & Interrupted \\
\hline S2.8 & 5.0 & 1.80 & $1,002.6$ & 2.83 & 105.2 & 65 & $d / h_{\text {outlet }}=0$ & Interrupted \\
\hline
\end{tabular}



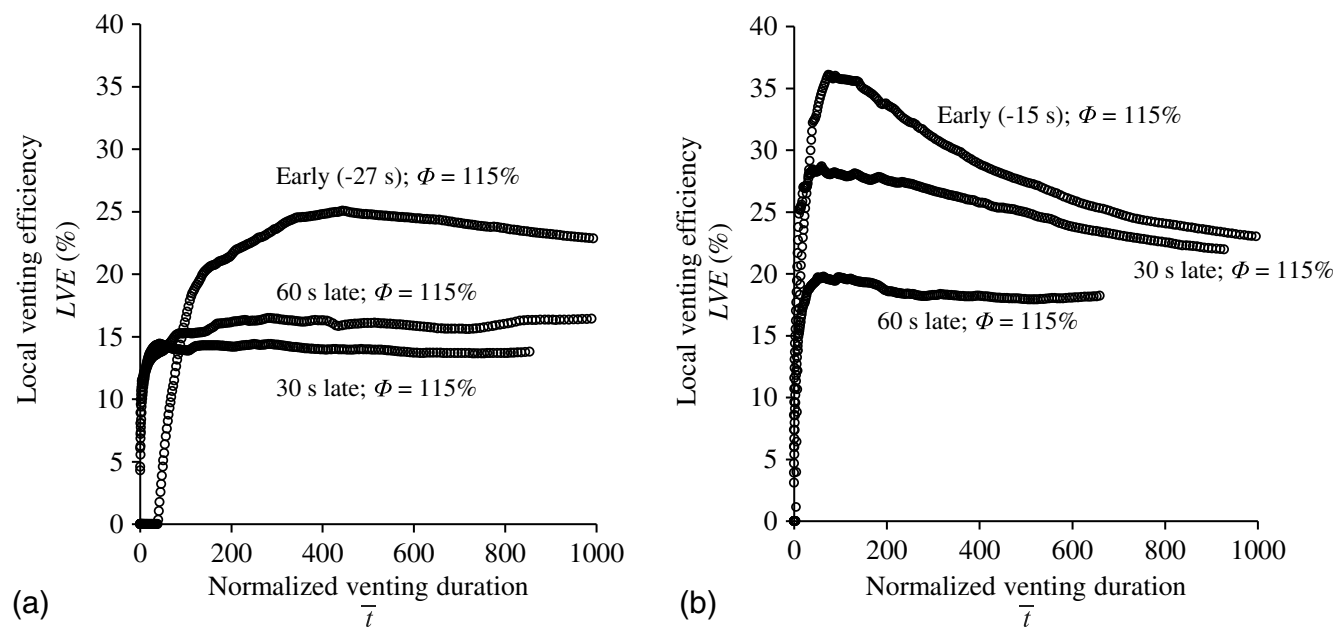

Fig. 5. LVE for early and late venting for (a) $S=2.4 \%$ (tests S1.1, S1.4, and S1.5); and (b) $S=5.0 \%$ (tests S2.1, S2.5, and S2.6).
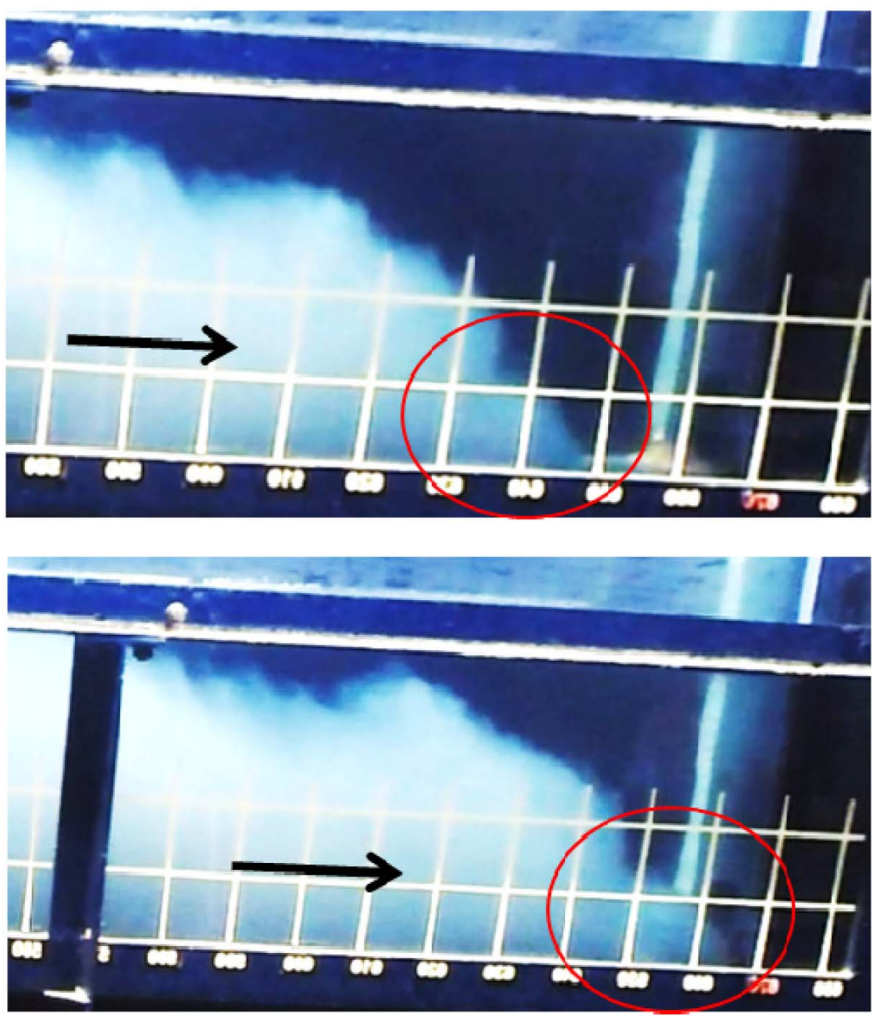

Fig. 6. Head of turbidity current at two different time steps $(\Delta t=5 \mathrm{~s})$ (test S2.1) ahead of arrival of current at outlet and while reaching. Circles highlight triangular-shaped head.

local. Moreover, the LVE values obtained when venting after $60 \mathrm{~s}$ were slightly larger than the LVE values obtained when venting after $30 \mathrm{~s}$ for $S=2.4 \%$. The opposite results were obtained with the $5.0 \%$ slope. Therefore, the LVE for late venting might be slopedependent. In any case, venting after the arrival of the turbidity current and the formation of the muddy lake should be avoided.

\section{Local Venting Efficiency: Early Venting versus In-Time Venting}

In the following, the LVE obtained with the early venting with $\Phi=$ $115 \%$ is compared with that of the in-time venting with $\Phi=100 \%$,

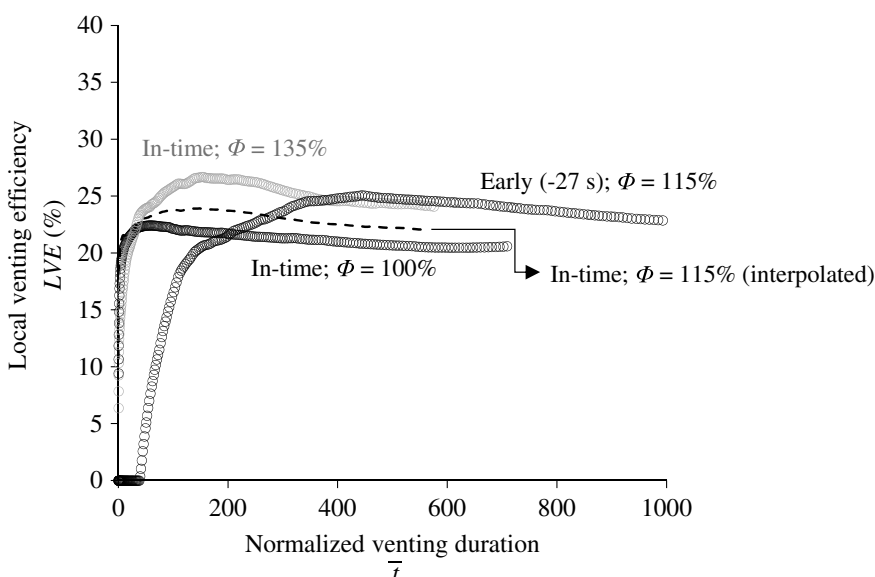

Fig. 7. LVE for early venting and in-time venting for $S=2.4 \%$ (tests $\mathrm{S} 1.1, \mathrm{~S} 1.2$, and $\mathrm{S} 1.3$ ).

$\Phi=115 \%$, and $\Phi=135 \%$. Note that the venting degree $\Phi=$ $100 \%$ was previously found to be the optimal venting degree when in-time venting is performed on a horizontal bed (Chamoun et al. 2017a), and $\Phi=135 \%$ the optimal venting degree for in-time venting on $2.4 \%$ and $5.0 \%$ slopes (Chamoun et al. 2017b).

Figs. 7 and 8 show that early venting was not efficient at the beginning of the operation (before the current reached the outlet) since the outlet's streamlines could not accelerate the current and clear water was lost. In other words, no sediments were vented before the current closely approached the bottom outlet. This is more notable with the $2.4 \%$ slope where the approaching current was slightly slower than with the $5.0 \%$ slope and therefore the time between the opening of the outlet and the arrival of the current to the outlet was longer. This resulted in greater water loss at the beginning of the operation. However, over the longer term, although the current was not accelerated, the efficiency values obtained with early venting and in-time venting became similar for both slopes.

Based on these results, and since the influence of the outlet's flow field during venting is local, it can be expected that starting venting much earlier than the arrival of the current at the dam would result in high water loss. The earlier the opening, the longer the duration at the beginning of venting where the LVE is low or null. Therefore, venting should be timed as close as possible to the 


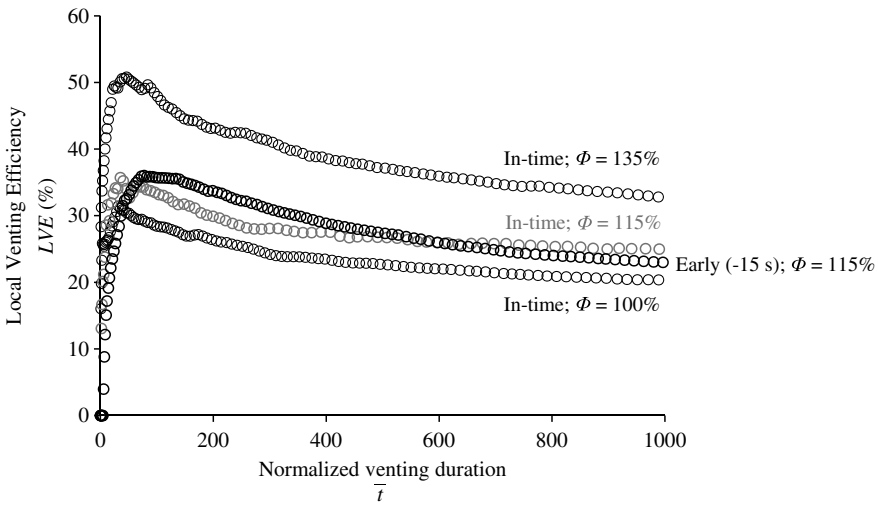

Fig. 8. LVE for early venting and in-time venting for $S=5.0 \%$ (tests S2.1, S2.2, S2.3, and S2.4).

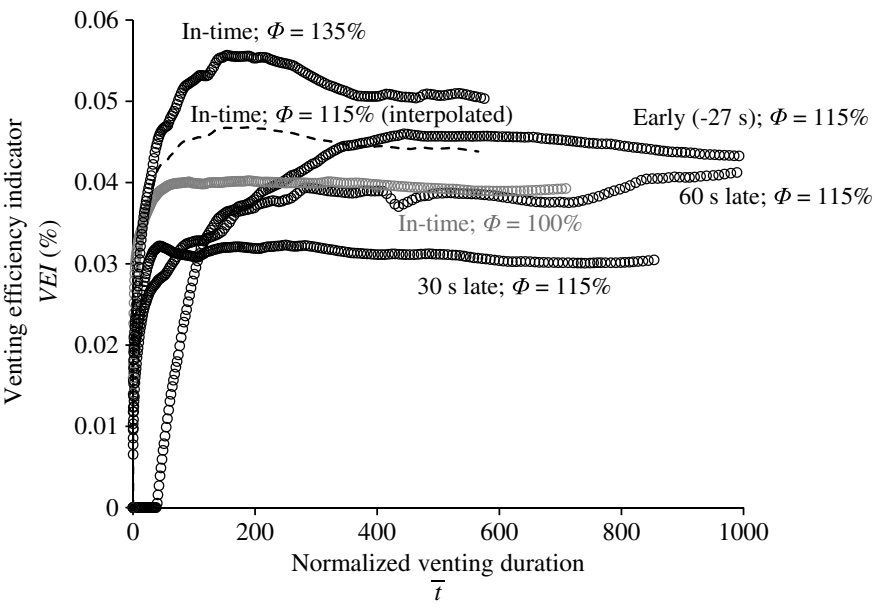

Fig. 9. VEI for different venting timings and venting degrees for $S=2.4 \%$. (tests $\mathrm{S} 1.1$ to $\mathrm{S} 1.5$ ).

arrival of the current at the dam, if possible, in order to ensure high efficiency from the beginning and throughout venting.

After a certain venting duration, flow conditions tend toward steadiness because inflow and outflow are steady and the muddy lake formed is partially evacuated and partially reflected upstream (before settling). Therefore, the quasi-steady values of LVE reached before the end of these tests can be considered as a reference state when projecting to longer venting durations. The long-term change that might affect this steadiness could be due to the sediments slowly settling in the upstream vicinity of the outlet and causing its partial clogging.

\section{Venting Efficiency Indicator}

The VEI in time obtained for all the tests performed on the same slope are shown in Figs. 9 and 10. For both slopes, an early venting resulted in higher efficiency than late venting in terms of sediments released and water loss. For $S=5.0 \%$, early venting produced a higher VEI just a few seconds after the beginning of the operation (the time needed for the current to reach the dam). With $S=2.4 \%$, the current was slightly slower and therefore the VEI of early venting required more time to surpass the VEI curves corresponding to late venting. The VEI results confirm the LVE results.

Furthermore, in-time venting with $\Phi=115 \%$ leads to a closely similar or slightly higher efficiency than venting before the arrival

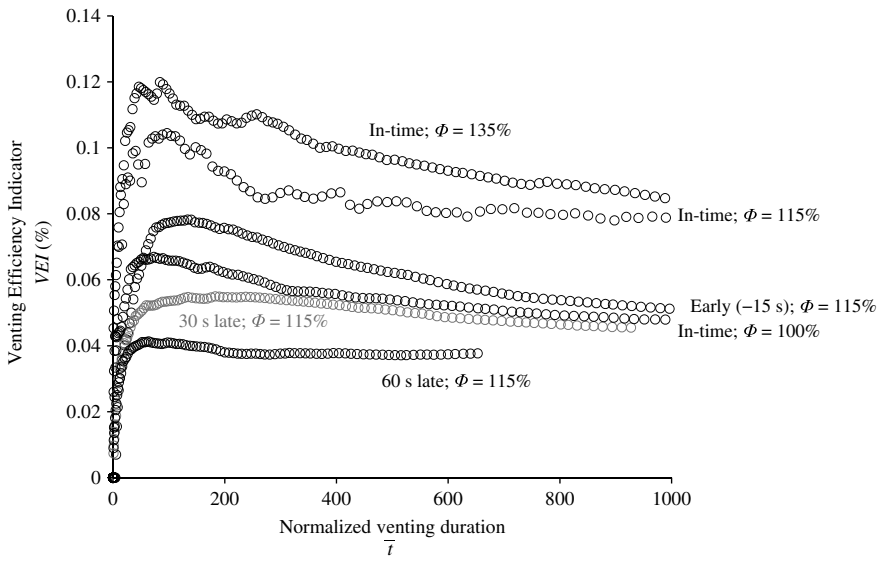

Fig. 10. VEI for different venting timings and venting degrees for $S=5.0 \%$. (tests S2.1 to S2.6).

of the current. Hence, in-time venting has the advantage of directly releasing sediments since the beginning of the operation. In contrast, early venting is not efficient before the current has reached the outlet, as concluded from both LVE and VEI values. Therefore, the optimal timing for venting turbidity currents in terms of sediments and water loss is when the turbidity current arrives at the outlet.

\section{Required Venting Duration after the End of the Flood}

In previous research, the typical behavior of outflow concentrations was experimentally evaluated when venting was performed with continuously fed turbidity currents (e.g., Chamoun et al. 2017b; Lee et al. 2014). It is characterized by a first phase of increasing concentration followed by a quasi-steady state. An example is shown in Fig. 11 using a venting degree $\Phi=135 \%$ for the two slopes $S=2.4 \%$ and $S=5.0 \%$, applying in-time venting. In this paper, up to this point, in all the tests discussed, the turbidity currents were all continuously fed. To examine the maximum duration of venting after the flood ending, the latter was experimentally simulated by interrupting the inflow.

In the following, two tests were performed where the turbidity current inflow discharge was stopped after around $t_{\text {cut }}=130 \mathrm{~s}$ of venting. Two venting degrees were tested: $\Phi=30 \%$ and $\Phi=65 \%$ with relatively long venting durations due to the low venting degrees chosen. In both cases, the concentration was observed to decrease once the inflow was interrupted (Figs. 12 and 13). In fact, the muddy lake formed in the vicinity of the outlet died out due to sediment settling as well as sediment evacuation through the outlet. Nevertheless, based on the trend lines in Figs. 12 and 13, the rate of outflow concentration decay after the interruption of the inflow was higher for $\Phi=65 \%$ (8\%o) than for $\Phi=30 \%$ (4\%o). The intercept values of the trend lines represent the maximum outflow concentration reached before the inflow was cut off. This result can be explained by the fact that with $\Phi=65 \%$, larger amounts of sediment are released from the muddy lake than with $\Phi=30 \%$. Therefore, the muddy lake tends to fade away faster. In Figs. 12 and 13, the linear trend lines of outflow concentrations after the inflow interruption are extrapolated. The time needed for the outflow concentration to decrease again to the lowest value measured at the beginning of venting $(1.7 \mathrm{~g} / 1$ in the tests; the reservoir's natural concentration in the prototype) can be concluded for each case (Table 3). Compared to $\Phi=65 \%$, the test with $\Phi=$ $30 \%$ requires more or less double the time for the concentration to decrease. 

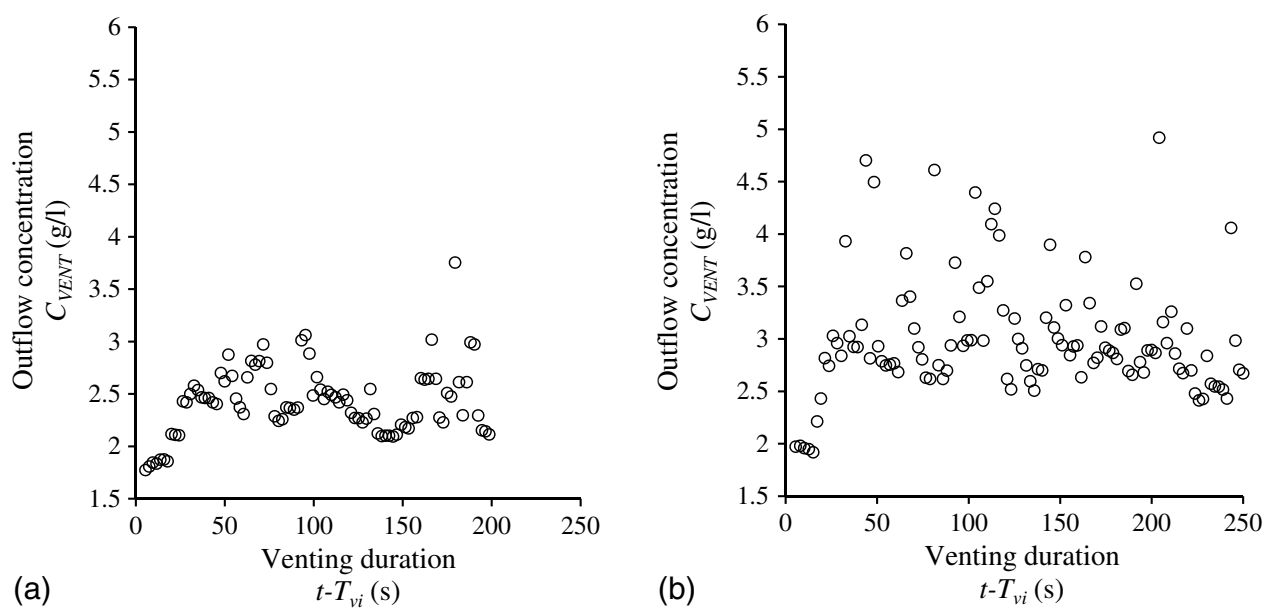

Fig. 11. Outflow concentration as a function of venting duration for a venting degree $\Phi=135 \%$ and for bed slopes: (a) $S=2.4 \%$; and (b) $S=5.0 \%$ for a continuously fed turbidity current and in-time venting. (tests S1.3 and S2.4).

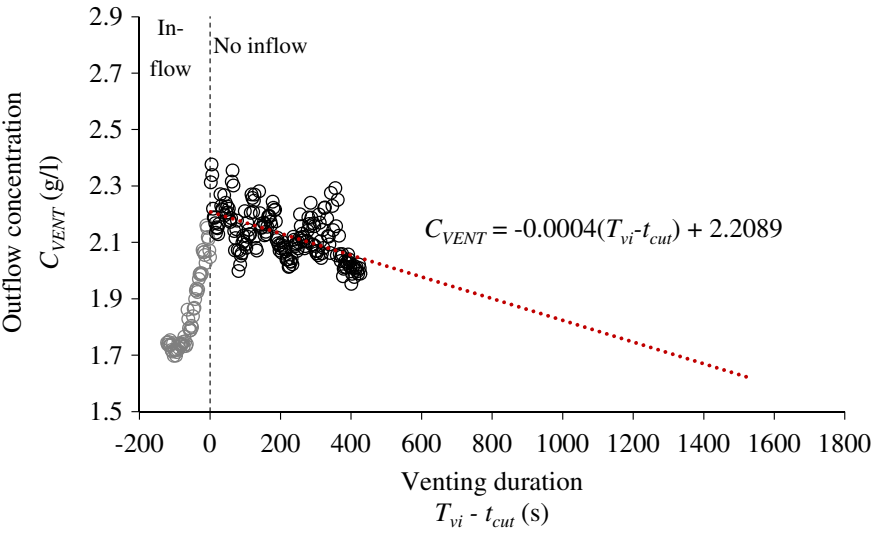

Fig. 12. Outflow concentrations for a venting degree $\Phi=30 \%$ on a $5.0 \%$ slope over time. Gray circles represent the outflow concentrations before inflow discharge was stopped. Black circles show outflow concentrations after turbidity current inflow was stopped. (test S2.7).

For practical applications, the inflow interruption corresponds to the end of a flood generating a turbidity current. The results in Figs. 12 and 13 show that the muddy lake upstream of the outlet can still be vented for a certain time after the end of the inflow. Comparing Fig. $12(\Phi=30 \%)$ with Fig. $13(\Phi=65 \%)$, it can be seen that this time depends on the venting degree $\Phi$.

After the inflow interruption, the muddy lake slowly disappeared. Part of its sediment was settling and another part was vented after the inflow ceased. The development of the muddy lake at different time steps after the inflow stopped is shown in Fig. 14. Fig. 14(a) corresponds to the time at which the inflow was interrupted. The time step between Figs. 14(a and b) is $\Delta t=125 \mathrm{~s}$. Before that, no visual changes could be detected. For the rest of the subfigures, $\Delta t=5 \mathrm{~s}$. In the opposite case where inflow was not limited in time, the muddy lake slowly increased in size and expanded upstream of the outlet (more or less, depending on the slope of the flume).

\section{Sediment Deposition}

The depositometer provides the total deposit at each bottom electrode. The deposition $m_{\text {dep }}$ measured at all bottom electrodes is

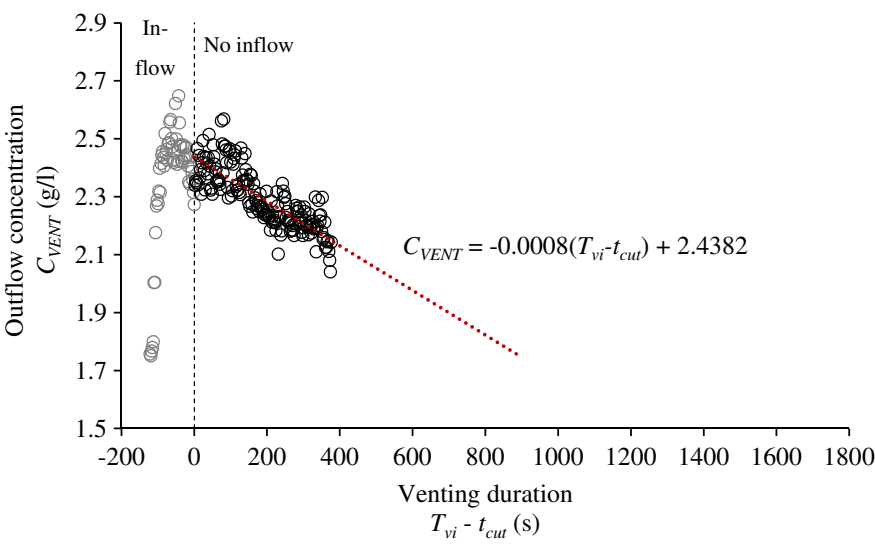

Fig. 13. Outflow concentrations for a venting degree $\Phi=65 \%$ on a $5.0 \%$ over time slope. Gray circles represent outflow concentrations before inflow discharge was stopped. Black circles show outflow concentrations after turbidity current inflow was stopped. (test S2.8).

Table 3. Time required for outflow concentrations to decrease after the inflow interruption

\begin{tabular}{lcc}
\hline Test & $\begin{array}{c}\text { Venting duration } \\
\text { before interruption }(\mathrm{s})\end{array}$ & $\begin{array}{c}\text { Occurrence of } \\
\text { lowest concentration } \\
\text { value after flood end (s) }\end{array}$ \\
\hline S2.7 & 130 & 1,272 \\
S2.8 & 130 & 923 \\
\hline
\end{tabular}

summed up at each time step and is shown as a function of the test duration in Fig. 15. One of the cases where inflow was stopped (S2.7) is compared with one of the cases where inflow was continuous during venting (S2.2).

The time during which the inflow ceased corresponds to the black circles in Fig. 15(a). As soon as the inflow stopped, the rate of deposition decreased, the curve flattened, revealing that the remaining suspended sediments deposited. The rate of deposition dropped from 19.6 to $1.45 \mathrm{~g} / \mathrm{s}$, decreasing 13.5 times. The fast dissipation of the current could be also visually seen through the transparent walls of the main flume once the inflow was stopped. In the opposite case where the turbidity current was continuously fed, 


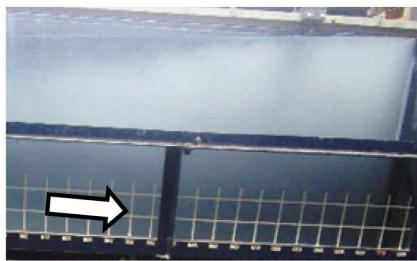

(a)

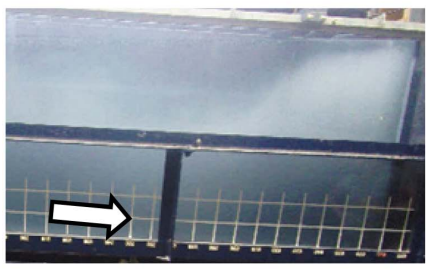

(e)

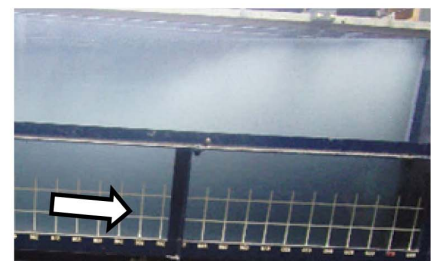

(b)

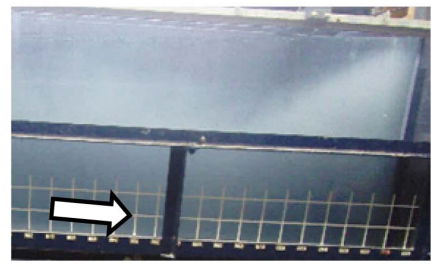

(f)

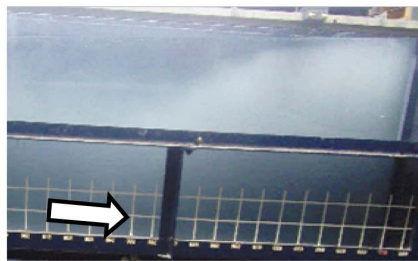

(c)

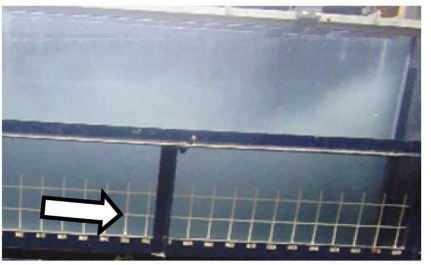

(g)

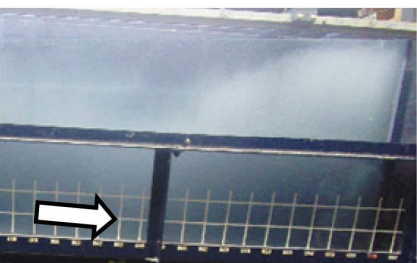

(d)

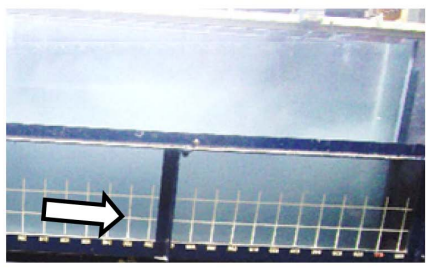

(h)

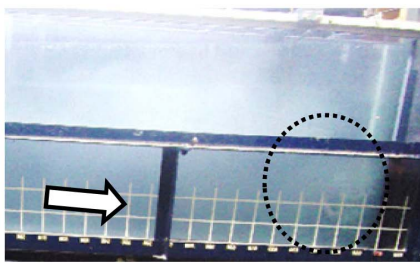

(i)

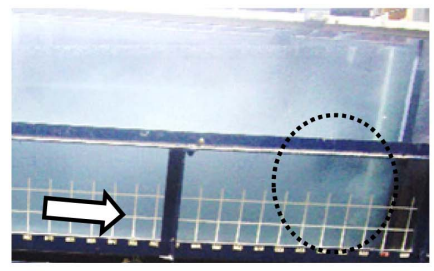

(j)

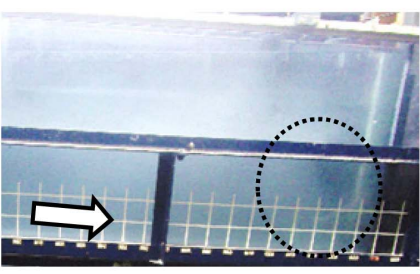

(k)

Fig. 14. Muddy lake disappearing after cutting off the inflow; for (a) and (b), $\Delta \mathrm{t}=125 \mathrm{~s}$ and from (c)-(k), $\Delta \mathrm{t}=5 \mathrm{~s}$. Circles highlight location where muddy lake can be seen to die out (test S2.8).
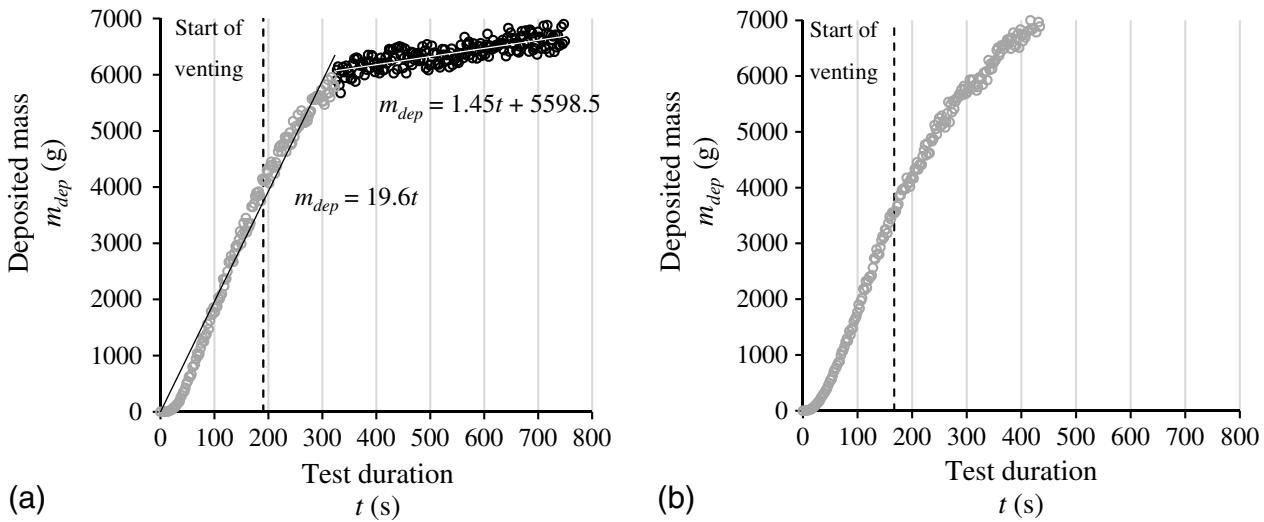

Fig. 15. Mass of sediments deposited as a function of duration of test for a slope $S=5.0 \%$ : (a) $\Phi=30 \%$ with inflow limited in time (test S2.7); and (b) $\Phi=100 \%$ with continuous inflow (test S2.2). Gray circles represent deposited mass before inflow was stopped. Black circles show deposited mass after inflow ceased. Dashed line corresponds to start of venting.

Table 4. Settling velocity relative to front velocity $v_{s} / U_{f}$ for each bed slope compared with $\sin \alpha$

\begin{tabular}{|c|c|c|c|c|}
\hline \multirow{2}{*}{$\begin{array}{l}\text { Bed slope } \\
S(\%)\end{array}$} & \multirow{2}{*}{$\begin{array}{l}\text { Slope angle } \alpha \\
\text { (degrees) }\end{array}$} & \multicolumn{2}{|c|}{$v_{s} / U_{f}$} & \multirow[b]{2}{*}{$\sin a$} \\
\hline & & Min & Max & \\
\hline 2.4 & 1.4 & $0.030(>0.02)$ & $0.070(>0.02)$ & 0.0 \\
\hline 5.0 & 2.9 & $0.034(<0.05)$ & $0.075(>0.05)$ & 0.05 \\
\hline
\end{tabular}

the deposition kept increasing following more or less the same trend [Fig. 15(b)].

After the inflow discharge is stopped, turbidity currents tend to die out, particularly on smooth beds where no sediments can be eroded to feed the current. The currents produced in the present study all decelerated (Chamoun et al. 2017a). The front velocity $U_{f}$ estimated using the video recordings decreased over time for both slopes. This is due to high rates of deposition rendering the currents less and less buoyant and unable to suspend the sediments they contain. This capacity of the turbidity currents to suspend the sediments can be assessed by Bagnold's autosuspension criterion (Bagnold 1962), expressed by $v_{s} / U_{f}<\sin \alpha$ (where $\alpha$ is the bed slope angle in degrees). Table 4 summarizes the values of $v_{s} / U_{f}$ for each bed slope. The minimum and maximum values of $v_{s} / U_{f}$ correspond to the maximum and minimum values of $U_{f}$, respectively. It can be concluded that $v_{s} / U_{f}>\sin \alpha$ most of the time, which explains the high depositional behavior of the turbidity currents. 


\section{Conclusions and Recommendations}

Bottom outlets are vital release structures that can lower the reservoir level in case of an emergency and therefore ensure the safety of dams (Schleiss et al. 2016; Schleiss and Pougatsch 2011). If a bottom outlet is clogged by sediments and its use is hindered, then the safety of the dam may be endangered. Turbidity currents are often the main cause not only for the blockage of bottom outlets but also of water intakes by sediments. Therefore, venting of turbidity currents through bottom outlets is not only important in terms of safety but also for the sustainable use of reservoirs. In the present study, the opening timing of the bottom outlet during a venting operation was experimentally investigated using two different reservoir bed slopes $S$. The interruption of the inflow representing the end of the turbidity current flow was also tested while venting was maintained.

Based on the analysis of the LVE and the VEI, considering sediment release and water loss, venting should ideally begin as soon as the turbidity current reaches the vicinity of the bottom outlet. However, considering that the time required to open the gate and for the flow field to establish is around 5-10 min, and that the common turbidity current traveling velocities are between 30 and $100 \mathrm{~cm} / \mathrm{s}$ (De Cesare 1998; Khripounoff et al. 2003; Lambert and Giovanoli 1988; Xu 2010), turbidity currents should be ideally detected around $300 \mathrm{~m}$ upstream of the dam. In other words, once the turbidity current is identified at this distance, the gate should be opened to allow for in-time venting, leading to the highest sediment release efficiency. The detection of the current should be done through turbidity and velocity measurements in the reservoir. A list of the most common instruments [e.g., turbidimeters, multibeam echo sounders, acoustic Doppler current profilers (ADCPs)] used by practitioners on the field for turbidity current detection can be found in Chamoun et al. (2016b). In case of lack of velocity measurements, which are often difficult to perform, the travel time of the turbidity current can be also estimated using a numerical model calibrated based on field data.

Additionally, early venting was shown to be more efficient than late venting. When the outlet is opened before the arrival of the current, even though no acceleration of the current can be observed, the potential flow field upstream of the operating outlet is better developed. This renders the venting of the current smoother and therefore the transit of the currents more efficient. In the case of late opening, the sediments in the muddy lake start to settle before venting has started, rendering their release almost impossible. As a result, if not enough field data is available for in-time venting, early venting is preferred to late venting.

Furthermore, venting should last at least as long as the flood duration. However, once the flood ends, the suspended muddy lake formed upstream of the dam does not instantaneously settle. Therefore, to avoid sedimentation and clogging of the bottom outlet and intake over the long term, venting should not be immediately stopped after the end of the flood. The duration of the venting should last after the end of inflow and before outflow concentrations decrease to the initial reservoir concentration values. This duration depends on the venting degree. With a $65 \%$ venting degree, this duration was almost two times shorter than that with a $30 \%$ degree in which the muddy lake could last longer before settling out or being evacuated. Additionally, the increasing rate of the total sediment deposition immediately dropped 13.5 times after the end of the turbidity current inflow. After a certain time, the cumulated mass of sediment deposit is expected to reach a constant value because no sediments will be available to settle. The time it takes for the total deposition to reach this steady state is directly linked to the settling velocity of the material. In future research, it would be useful to test other parameters that might potentially influence the maximum duration of venting after the end of inflow. These parameters include the geometry of the reservoir and the thalweg's slope near the dam close to the outlet.

Finally, if performed under controlled conditions, venting of turbidity currents is an economical and environmentally friendly technique of sediment mitigation in reservoirs. Well-timed venting operations applying adequate outflow discharges for an optimized duration helps minimize water loss while reducing sedimentation in reservoirs and providing necessary sediments to the downstream river.

\section{Acknowledgments}

The funding of this research study entitled Efficiency of turbidity currents venting under varied outflow discharge was provided by Swisselectric Research with the additional support of the Swiss Committee on Dams.

\section{Notation}

The following symbols are used in this paper:

$B_{0}=$ initial buoyancy flux of the turbidity current;

$C_{V E N T}=$ outflow concentration;

$C_{T C}=$ turbidity current's initial volumetric inflow concentration;

$d=$ distance of the turbidity current from the outlet at which early venting starts;

$d_{10}=$ grain diameter for which $10 \%$ of sediments have smaller diameters;

$d_{50}=$ mean grain size diameter;

$d_{90}=$ grain diameter for which $90 \%$ of sediments have smaller diameters;

$g=$ gravitational acceleration;

$g_{a p p}^{\prime}=$ reduced gravitational acceleration of the turbidity current approaching the outlet;

$g_{0}^{\prime}=$ initial reduced gravitational acceleration of the turbidity current;

$h_{\text {outlet }}=$ height of the bottom outlet;

$m_{\text {dep }}=$ total mass of sediments deposited along the flume at a time $t$ of the test;

$Q_{T C}=$ turbidity current inflow discharge;

$Q_{V E N T}=$ venting outflow discharge;

$Q_{R E S}=$ residual discharge;

$q_{T C}=$ turbidity current specific inflow discharge;

$S=$ flume's bed slope;

$T_{v i}=$ beginning of venting;

$t=$ duration of the test;

$t_{\text {after }}=$ time at which late venting starts after the arrival of the turbidity current at the outlet;

$t_{c u t}=$ duration of venting after which turbidity current inflow is cut (130 s);

$\bar{t}=$ normalized venting duration;

$U_{f}=$ front velocity of the turbidity currents;

$v_{s}=$ sediment settling velocity;

$\alpha=$ flume's slope angle;

$\rho_{s}=$ density of sediment material;

$\rho_{w}=$ density of clear water; 
$\rho_{t 0}=$ initial density of the turbidity current; and

$\Phi=$ venting degree

\section{Supplemental Data}

Appendix S1 is available online in the ASCE Library (www .ascelibrary.org).

\section{References}

Annandale, G. W. 2005. Reservoir sedimentation. Chichester, UK: Wiley. Antoine, G., M. Jodeau, B. Camenen, M. Esteves, J. Nemery, and F. Lauters. 2013. "Estimation des flux de matières en suspension lors des chasses hydrauliques de l'Arc de 2006 à 2011." [In French.] $L a$ Houille Blanche 99 (4): 43-49. https://doi.org/10.1051/lhb/2013032.

Bagnold, R. A. 1962. "Auto-suspension of transported sediment; turbidity currents." Proc. R. Soc. London, Ser. A 265 (1322): 315-319. https://doi .org/10.1098/rspa.1962.0012.

Basson, G., and A. Rooseboom. 1997. Dealing with reservoir sedimentation: Prepared for the water research commission. WRC Rep. No. TT 91/97. Pretoria, South Africa: Water Research Commission.

Boillat, J.-L., J. Dubois, G. De Cesare, and E. Bollaert. 2000. "Sediment management examples in Swiss Alpine reservoirs." In Proc., Int. Workshop and Symp. Reservoir Sedimentation Management. Tokyo.

Boillat, J.-L., and H. Pougatsch. 2000. "State of the art of sediment management in Switzerland." In Proc., Int. Workshop and Symp. on Reservoir Sedimentation Management, 143-153. Tokyo.

Brandt, S. A. 2000. "A review of reservoir desiltation." Int. J. Sediment Res. 15 (3): 321-342.

Brown, C. B. 1950. Sediment transportation. Edited by H. Rouse. New York: Wiley.

Brune, G. M. 1953. "Trap efficiency of reservoirs." Am. Geophys. Union 34 (3): 407-418. https://doi.org/10.1029/TR034i003p00407.

Cao, Z., J. Li, G. Pender, and Q. Liu. 2015. "Whole-process modeling of reservoir turbidity currents by a double layer-averaged model." J. Hydraul. Eng. 141 (2): 4014069. https://doi.org/10.1061/(ASCE)HY .1943-7900.0000951.

Chamoun, S., G. De Cesare, and A. J. Schleiss. 2016a. "Managing reservoir sedimentation by venting turbidity currents: A review." Int. J. Sediment Res. 31 (3): 195-204. https://doi.org/10.1016/j.ijsrc.2016 .06 .001

Chamoun, S., G. De Cesare, and A. J. Schleiss. 2016b. "Venting turbidity currents for the sustainable use of reservoirs." Int. J. Hydropower Dams 23 (5): 64-69.

Chamoun, S., G. De Cesare, and A. J. Schleiss. 2017b. "Management of turbidity current venting in reservoirs under different bed slopes." J. Environ. Manage. 204 (Pt 1): 519-530. https://doi.org/10.1016/j .jenvman.2017.09.030.

Chamoun, S., G. De Cesare, and A. J. Schleiss. 2017a. "Venting of turbidity currents approaching a rectangular opening on a horizontal bed." J. Hydraul. Res. 56 (1): 44-58. https://doi.org/10.1080/00221686 2017.1289266

Chamoun, S., J. Zordan, G. De Cesare, and M. J. Franca. 2016c. "Measurement of the deposition of fine sediments in a channel bed." Flow Meas. Instrum. 50 (4): 49-56. https://doi.org/10.1016/j .flowmeasinst.2016.06.008.

Chen, J., and K. Zhao. 1992. "Sediment management in Nanqin reservoir." Int. J. Sediment Res. 7 (3): 71-84.

Crowder, B. M. 1987. "Economic costs of reservoir sedimentation: A regional approach to estimating cropland erosion damage." J. Soil Water Conserv. 42 (3): 194-197.

De Cesare, G. 1998. "Alluvionnement des retenues par courants de turbidité." [In French.] Ph.D. thesis, Ecole Polytechnique Fédérale de Lausanne EPFL.

De Cesare, G., A. J. Schleiss, and F. Hermann 2001. "Impact of turbidity currents on reservoir sedimentation." J. Hydraul. Eng. 127 (1): 6-16.

Espa, P., M. L. Brignoli, G. Crosa, G. Gentili, and S. Quadroni. 2016. "Controlled sediment flushing at the Cancano Reservoir (Italian Alps):
Management of the operation and downstream environmental impact." J. Environ. Manage. 182 (18): 1-12. https://doi.org/10.1016/j.jenvman 2016.07.021.

Fan, J. 1960. "Experimental studies on density currents." Sci. Sin. 4 (2): 275-303.

Fan, J. 1986. "Turbid density currents in reservoirs." Water Int. 11 (3): 107-116. https://doi.org/10.1080/02508068608686404.

Fiock, L. R. 1934. "Records of silt carried by the Rio Grande and its accumulation in Elephant Butte Reservoir." EOS, Trans. Am. Geophys. Union 15 (2): 468-473. https://doi.org/10.1029/TR015i002p00468.

Graf, W. H., and M. S. Altinakar. 1995. "Courants de turbidité." [In French.] La Houille Blanche 81 (7): 28-37. https://doi.org/10.1051/lhb /1995065.

Kantoush, S. A., and T. Sumi 2010. "River morphology and sediment management strategies for sustainable reservoir in Japan and European Alps." Annu. Disaster Prev. Res. Inst., Kyoto, Japan 821-839.

Khripounoff, A., A. Vangriesheim, N. Babonneau, P. Crassous, B. Dennielou, and B. Savoye. 2003. "Direct observation of intense turbidity current activity in the Zaire submarine valley at $4000 \mathrm{~m}$ water depth." Mar. Geol. 194 (3): 151-158. https://doi.org/10.1016/S0025 $-3227(02) 00677-1$.

Kneller, B., and C. Buckee. 2000. "The structure and fluid mechanics of turbidity currents: A review of some recent studies and their geological implications." Supplement, Sedimentology 47 (S1): 62-94. https://doi org/10.1046/j.1365-3091.2000.047s1062.x.

Lambert, A., and F. Giovanoli. 1988. "Records of riverborne turbidity currents and indications of slope failures in the Rhone Delta of Lake Geneva." Limnol. Oceanogr. 33 (3): 458-468. https://doi.org/10 .4319/lo.1988.33.3.0458.

Lee, F. Z., J. S. Lai, Y. C. Tan, and C. C. Sung. 2014. "Turbid density current venting through reservoir outlets." KSCE J. Civ. Eng. 18 (2): 694-705. https://doi.org/10.1007/s12205-014-0275-y.

Lee, H.-Y., and W.-S. Yu. 1997. "Experimental study of reservoir turbidity current." J. Hydraul. Eng. 123 (6): 520-528. https://doi.org/10.1061 /(ASCE)0733-9429(1997)123:6(520).

Meiburg, E., and B. Kneller. 2010. "Turbidity currents and their deposits." Annu. Rev. Fluid Mech. 42 (1): 135-156. https://doi.org/10.1146 /annurev-fluid-121108-145618.

Morris, G., and J. Fan. 1997. Reservoir sedimentation handbook: Design and management of dams, reservoirs, and watersheds for sustainable use. New York: McGraw-Hill.

Müller, M. 2012. "Influence of in- and outflow sequences on flow patterns and suspended sediment behavior in reservoirs." Ph.D. thesis, Ecole Polytechnique Fédérale de Lausanne EPFL.

Oehy, C. 2003. "Effects of obstacles and jets on reservoir sedimentation due to turbidity currents." Ph.D. thesis, Laboratory of Hydraulic Constructions, Ecole Polytechnique Fédérale de Lausanne.

Palmieri, A., F. Shah, G. Annandale, and A. Dinar. 2003. Reservoir conservation volume I: The RESCON approach economic and engineering evaluation of alternative strategies for managing sedimentation in storage reservoirs. Washington, DC: World Bank.

Palmieri, A., F. Shah, and A. Dinar. 2001. "Economics of reservoir sedimentation and sustainable management of dams." J. Environ. Manage. 61 (2): 149-163. https://doi.org/10.1006/jema.2000.0392.

Schleiss, A., G. De Cesare, and J. J. Althaus. 2010. "Verlandung der Stauseen gefährdet die nachhaltige Nutzung der Wasserkraft." [In German.] Wasser, Energie, Luft-Eau, Energie, Air 102 (1): $31-40$.

Schleiss, A. J., M. J. Franca, C. Juez, and G. De Cesare. 2016. "Reservoir sedimentation. Vision paper." J. Hydraul. Res. 54 (6): 595-614. https:// doi.org/10.1080/00221686.2016.1225320.

Schleiss, A. J., and H. Pougatsch. 2011. "Les barrages: Du projet à la mise en service." In Vol. 17 of Traité de Génie Civil de l'Ecole Polytechnique Fédérale de Lausanne. [In French.] Lausanne, Switzerland: Presses polytechniques et universitaires romandes.

Schneider, J., H. Badura, W. Troy, and H. Knoblauch. 2007. "Determination of parameters for venting turbidity currents." IAHR Congr. 32 (1): 425. 
Sloff, C. J. 1991. Communications on hydraulic and geotechnical engineering. Delft, Netherlands: Faculty of Civil Engineering, Delft Univ. of Technology.

Vanoni, V. A. 2006. Sedimentation engineering. Reston, VA: ASCE.

Wan, X. Y., G. Q. Wang, P. Yi, and W. M. Bao. 2010. "Similarity-based optimal operation of water and sediment in a sediment-laden reservoir." Water Resour. Manage. 24 (15): 4381-4402. https://doi.org/10.1007 /s11269-010-9664-2.

Wang, Z., and C. Hu. 2009. "Strategies for managing reservoir sedimentation.” Int. J. Sediment Res. 24 (4): 369-384. https://doi.org/10.1016 /S1001-6279(10)60011-X.
Wen Shen, H. 1999. "Flushing sediment through reservoirs." J. Hydraul. Res. 37 (6): 743-757.

Wüest, A. 2010. "Downstream relevance of reservoir management." In Vol. 6 of Alpine waters: The handbook of environmental chemistry, 235-246. Berlin: Springer.

Xu, J. P. 2010. "Normalized velocity profiles of field-measured turbidity currents." Geology 38 (6): 563-566. https://doi.org/10.1130/G30582.1.

Yu, W.-S., S. M. Hsu, and K.-L. Fan. 2004. "Experiments on selective withdrawal of a codirectional two-layer flow through a line sink." J. Hydraul. Eng. 130 (12): 1156-1166. https://doi.org/10.1061 /(ASCE)0733-9429(2004)130:12(1156). 